\title{
Necessity of vasoconstrictors for esophageal variceal bleeding after endoscopic ligation: A systematic review and meta-analysis
}

Jen-Hao Yeh

EDA hospital

Gin Lo ( $\nabla$ ghlo@kimo.com )

I-Shou University https://orcid.org/0000-0001-7190-200X

Ru-Yi Huang

E-Da Hospital

Chih-Wen Lin

E-Da Hospital

Wen-Lun Wang

E-Da Hospital

Research article

Keywords: Acute variceal bleeding, Esophageal variceal ligation, Vasoconstrictor, Meta-analysis

Posted Date: December 13th, 2019

DOI: https://doi.org/10.21203/rs.2.18872/v1

License: (9) This work is licensed under a Creative Commons Attribution 4.0 International License.

Read Full License 


\section{Abstract}

\section{Background}

Several recent trials have suggested that the need for vasoconstrictors for preventing esophageal variceal bleeding may be considerably reduced after endoscopic variceal ligation (EVL). However, comprehensive systematic reviews on this topic are hardly available.

\section{Methods}

A meticulous literature review and meta-analysis were conducted using the databases of PubMed, Embase, and the Cochrane Library. Primary outcomes were initial hemostasis, rebleeding, mortality, and treatment failure within 5 days, and secondary outcomes were 6-week mortality and adverse events.

\section{Results}

Five randomized trials with 423 participants were included in the meta-analysis. The results revealed that the following outcomes were similar in groups that received only EVL and a standard combination regimen: initial hemostasis $(97.6 \%$ vs. $98.0 \%$, risk ratio $(R R)=1.00,95 \%$ confidence interval $(\mathrm{Cl})=0.97-$ 1.02), 5 -day rebleeding ( $15.9 \%$ vs. $6.6 \%, \mathrm{RR}=2.25,95 \% \mathrm{Cl}=0.87-5.77)$, treatment failure $(9.6 \%$ vs. $6.7 \%$, $\mathrm{RR}=1.43,95 \% \mathrm{Cl}=0.54--3.75), 5$-day mortality rates $(0$ vs. $0.7 \%, \mathrm{RR}=0.81,95 \% \mathrm{Cl}=0.09-6.87)$, and 6week mortality rates $(2.9 \%$ vs. $3.0 \%, \mathrm{RR}=0.88,95 \% \mathrm{Cl}=0.25-3.13)$. By contrast, sensitivity analysis suggested obvious clinical heterogeneity in 5-day rebleeding although an outlier study was identified.

\section{Conclusion}

In patients with acute esophageal variceal bleeding after EVL, 5-day and 6-week mortality rates were similar regardless of vasoconstrictor use. However, considering the controversial 5-day rebleeding rate, short course of vasoconstrictor use based on current evidence may be reasonable.

\section{Background}

Acute esophageal variceal bleeding is a major complication of portal hypertension, which is associated with considerably high morbidity and mortality (1). Although the prognosis of variceal bleeding has improved in recent years $(2,3)$, multidisciplinary care is required to optimize outcomes. Vasoconstrictor use is generally the first-line therapy for acute variceal bleeding (1), followed by endoscopic treatment. Endoscopic injection sclerotherapy (EIS) has been considered to be the first effective endoscopic treatment; however, rebleeding rates with EIS alone are high (4-6). Hence, the combined use of EIS and vasoconstrictors for up to 5 days has been recommended $(1,7)$.

In the past decade, endoscopic varices ligation (EVL) has replaced EIS as the treatment of choice because it has fewer complications and a lower rebleeding likelihood $(8,9)$. Because EVL is highly effective in arresting acute esophageal variceal bleeding, the optimal duration of vasoactive agent use 
after EVL has been debated (10). Furthermore, several studies have suggested that the outcomes of variceal bleeding after EVL with a short course ( $\leq 3$ days) of vasoconstrictor use or without vasoconstrictor use (only EVL) may be similar (11-16). Although two previous meta-analyses have supported the use of vasoconstrictors in addition to endoscopic treatment, one of the meta-analyses, by Banares et al. (17) focused on trials exclusively involving EIS, whereas the other meta-analysis by Yan et al. (18) did not include two randomized trials on $\operatorname{EVL}(12,19)$. We hypothesized that because the efficacy of EVL is superior to that of EIS, the need for subsequent vasoconstrictor use might be considerably reduced. Hence, we conducted a systematic review and meta-analysis to explore whether EVL alone has outcomes similar to those of standard therapy in patients with acute esophageal variceal bleeding.

\section{Materials And Methods}

\section{Study design and search strategy}

In this study, we included studies comparing outcomes of esophageal variceal bleeding after either standard combination therapy (EVL plus vasoactive agents for up to 5 days) or only EVL in patients with acute esophageal variceal bleeding. Two authors (JHY and GHL) independently conducted comprehensive literature searches by using three online database resources, namely PubMed, Embase,

and the Cochrane Library in November 2019. The search queries and keywords were "esophageal variceal bleeding AND endoscopic ligation" in all databases.

After excluding duplicate articles, the authors (JHY and WLW) proceeded with a manual review of references to retrieve relevant studies. The abstracts and full texts, if required, of all the records identified using the database searches were reviewed for eligibility. Articles were excluded if EVL was not administered as an endoscopic treatment, vasoactive agents were used without prior endoscopy in the control group, control and test groups received combination therapy involving vasoactive agents, gastric variceal bleeding was reported, outcomes within 5 days and during hospitalization were not reported, and EIS was used as the main endoscopic treatment.

\section{Data extraction and assessment of outcomes and validity}

The following data were extracted: name of first author, year of publication, country of origin, number and characteristics of participants, study design, treatment modality, dose and administration of vasoactive agents, primary outcomes, and secondary outcomes. The primary outcomes of these studies were initial hemostasis, 5-day rebleeding, 5-day mortality, and 5-day treatment failure, defined as persistent bleeding, rebleeding, or mortality after successful endoscopic hemostasis. The secondary outcomes were 6-week mortality rates, adverse events, hospital stay, and transfusion requirement. All data were extracted as originally stated or after appropriate calculations were conducted.

The included randomized clinical trials were independently reviewed by two authors (JHY and CWL) by using Cochrane Collaboration's risk of bias assessment tool (20). Any discrepancy observed in the review process was resolved after discussion with the corresponding author $(\mathrm{GHL})$. 


\section{Statistical analysis}

Statistical analyses were performed using Comprehensive Meta-Analysis version 3.3.070 (Biostat, Englewood, NJ, USA). In this study, risk ratios (RRs) were generally used for discrete variables, and the corresponding $95 \%$ confidence intervals ( $\mathrm{Cls}$ ) were used to compare the outcomes between the groups that received standard and short courses of vasoactive agents. For the outcomes with zero values in both groups, continuity correction was used to facilitate meta-analysis (21). The pooled effect sizes were considered statistically significant if a $p$ value of $<0.05$ was obtained, or the range of $95 \% \mathrm{Cl}$ excluded 1 for RR. In this study, a random-effects model was selected for pooled effect estimates because of the small number of studies included, which may have caused the random-effects model to underestimate the statistical heterogeneity and clinical heterogeneity based on different baseline study characteristics.

Statistical heterogeneity among studies was assessed using the I square $(R)$ statistic, which indicated the percentage of total variation and inconsistency across studies caused by heterogeneity rather than chance, and a high value generally suggested high heterogeneity. The presence of significant statistical heterogeneity was defined as $p<0.1$ in a chi-square test. Publication bias was evaluated using funnel plots, which involved plotting the natural logarithm of the RR against the inverse of the standard error for each study as well as the use of Egger's test (23), for which a $p$ value of $<0.1$ in a two-tailed test was considered a positive result. In this study, we used the 5-day rebleeding rate to examine the publication bias because it was reported in all the included studies. For all pooled results, sensitivity analysis was conducted by excluding one study at a time (24) to determine the robustness of the results, and additional analysis was performed to identify the source of heterogeneity.

\section{Results}

\section{Search results and included studies}

After excluding duplicate articles, we had 1532 potentially relevant records based on the search strategy and additional manual search. During subsequent review, 13 studies that met the inclusion criteria were further evaluated for eligibility, and five full-text articles from 1995 to 2015 were included in this metaanalysis $(12,14,19,25,26)$. The review process is illustrated using a flowchart of Preferred Reporting Items for Systematic Reviews and Meta-Analyses (PRISMA) (27) (Figure 1).

\section{Baseline characteristics of included studies}

All five included studies were prospective, randomized controlled trials with a total of 423 patients ( $84.8 \%$ men); the weighted-average age was 51.1 years, and $34 \%-55 \%$ of the patients had alcoholic cirrhosis; in addition, a substantial portion of the patients were classified as Child-Pugh class B (39\%$47 \%)$ or class C (24\%-55\%). Typical included patients exhibited cirrhosis with the first attack of acute esophageal variceal bleeding. Those who did not exhibit cirrhosis, exhibited hepatocellular carcinoma or portal vein thrombosis, or those who had previous variceal bleeding were generally excluded from these 
studies $(12,14,19,25,26)$. The baseline characteristics of patients are summarized in Table 1 and Table S1, and they were similar between the EVL and standard combination groups.

After the index bleeding episodes, endoscopic treatments were performed within 6 to 24 hours; and the three conducted studies after 2000 involved the use of multiband ligators for hemostasis $(12,14,19)$.

The rate of active spurting during the index endoscopy was similar in both groups ( $32 \%$ vs. $36 \%$ in EVL vs. standard combination group, $p=0.246$ ). Vasoconstrictors, including terlipressin, octreotide, and somatostatin, were prescribed either before (25) or after emergency endoscopy $(12,14,19,26)$. The dosages were in accordance with the recommendation of current international guidelines $(1,7)$, except for the study by Peng (19) in which terlipressin was prescribed at a dose of $1 \mathrm{mg}$ QD. In the control group that did not receive vasoconstrictors, proton pump inhibitor (12), propranolol (19), and placebo (14) were prescribed as concomitant medical therapy.

\section{Risk of bias assessment}

Risk of bias in each randomized clinical trial was evaluated using the Cochrane Collaboration's risk of bias assessment tool; the results are summarized in Table S2. Among these studies, only one had a double-blind design (14) and one was a single-blind study with respect to the examiner only (12). All studies generally had a ratio of 1:1 for randomization of participants; however, none of the studies described the detailed randomization and allocation concealment procedure.

\section{Primary outcomes: initial hemostasis and rebleeding, treatment failure, and mortality in the first 5 days}

The numbers of patients with major outcomes in each study are summarized in Table 2. Rate of initial hemostasis was reported in all articles, with the range from $93 \%-100 \%$, and the pooled estimate were almost the same between the EVL or standard combination groups $(97.6 \%$ vs. $98.0 \%, \mathrm{RR}=1.00,95 \% \mathrm{Cl}=$ $0.97-1.02$, Figure 2a).

Five-day rebleeding rates were also available in all the included studies, and most of them exhibited a nonsignificant RR during the meta-analysis except for the study by Sung et al. (25), which favored combination therapy. Although a trend toward higher rebleeding rates in the EVL group was observed, the pooled estimate was not statistically significant $(15.9 \%$ vs. $6.6 \%, \mathrm{RR}=2.25,95 \% \mathrm{Cl}=0.87-5.77, p=0.09$, Figure $2 b)$.

Mortality rate was presented as death within the first 5 days $(12,19,26)$ and in-hospital mortality $(14,25$, 26). The meta-analysis did not reveal a significant difference in 5 -day rebleeding rates $(0 \mathrm{vs} .0 .7 \%, \mathrm{RR}=$ $0.81,95 \% \mathrm{Cl}=0.09-6.87$, Figure $2 \mathrm{c})$ or in-hospital mortality rates $(11.2 \%$ vs. $6.8 \%, \mathrm{RR}=1.69,95 \% \mathrm{Cl}=$ $0.70-4.04$, Figure S1) between the groups. Treatment failure within 5 days was documented in all studies except for the study by Sung et al. (25). The pooled result showed that similar results were obtained using EVL alone and standard combination therapy (9.6\% vs. $6.7 \%, R R=1.43,95 \% \mathrm{Cl}=0.54-3.75$, Figure $2 \mathrm{~d}$ ). 
Six-week mortality was documented in three studies $(12,19,26)$. With meta-analysis, the 6-week mortality was similar between the EVL and standard combination groups $(2.9 \%$ vs. $3.0 \%, \mathrm{RR}=0.88,95 \% \mathrm{Cl}=0.25-$ 3.13, Figure 3). Adverse events of both groups were reported in three studies. In the study by Lee et al (26), cases of aspiration pneumonia (two and three in the EVL and standard combination groups, respectively) and one case of spontaneous bacterial peritonitis in the standard combination group were observed during hospitalization. By contrast, the study by Lo et al. reported a significantly larger number of patients with chest pain and abdominal pain in the standard combination group than in the EVL group $(22 / 60$ vs. $0 / 60, p<0.001)(12)$.

The length of hospital stay was also reported in two studies. Lee et al. (26) suggested significantly longer hospitalization in the EVL group than in the standard combination group ( $16 \pm 11$ vs. $11 \pm 4$ days, $p=0.028$ ), whereas Lo et al. (12) did not report any difference between the groups ( $8.8 \pm 3.8$ vs. $9.4 \pm 2.3$ days, $p=0.45)$. In addition, the duration of intensive care unit stay was similar in both the groups $(14$, 26). In terms of transfusion requirements, the need for transfusion in the standard combination and $E V L$ groups was similar $(14,19,25,26)$; however, the different parameters reported in each article precluded further meta-analysis.

\section{Sensitivity analysis and evaluation of publication bias}

Sensitivity analysis by excluding one study at a time was undertaken for meta-analysis of the primary outcomes. For initial hemostasis, 5-day mortality rates, and treatment failure, the pooled estimate did not exhibit significant changes during analysis. By contrast, significantly higher 5-day rebleeding rates were observed with $\mathrm{EVL}$ alone ( $14.7 \%$ vs. $2.7 \%, \mathrm{RR}=4.02,95 \% \mathrm{Cl}=1.76-9.20$, Figure $4 \mathrm{a})$ when the study of Kumar et al. (14) was excluded than when it was included; furthermore, cumulative analysis revealed that the pooled estimate favored the standard combination group until this study was included (Figure 4b). Excluding any other study did not result in significant changes from the initial meta-analysis. However, the difference in rebleeding rates was considerably smaller (9.6\% vs. $6.1 \%, \mathrm{RR}=1.26,95 \% \mathrm{Cl}=0.59$ 2.69) if the study by Sung et al. (25) was exluded, which was the only study showing significantly higher rebleeding in the EVL than in the standard group in this review.

Publication bias was assessed using pooled estimates of 5-day rebleeding (Figure 4c). Obvious bias was not observed on the funnel plot and Egger's test did not provide significant results (one-tailed $p=0.337$ ).

\section{Discussion}

For acute esophageal variceal bleeding, vasoconstrictors and endoscopic treatment and prophylactic antibiotics have been the standard of care $(1,7)$. Because the risk of rebleeding is highest in the first 5 days (28), vasoconstrictor use is generally recommended in this period. Studies have shown that EIS may result in paradoxical portal hypertension after treatment, and vasoconstrictors are useful for alleviating adverse effects of EIS $(29,30)$. By contrast, EVL is not associated with rebounding portal hypertension 
(31); therefore, it is considered to exhibit higher efficacy than EIS for hemostasis $(8,32)$. This is also supported in the trial by Kumar et al. (14); the hepatic venous pressure gradient was similar at baseline and after EVL.

Recently, a meta-analysis demonstrated a short course of vasoconstrictors use may have similar outcomes, in terms of hemostasis and very early rebleeding, as standard 5-day treatment after EVL for esophageal variceal bleeding. However, the contribution of this study to the conclusion regarding the efficacy of vasoconstrictors compared with the placebo was limited because it did not include all available trials. Hence, further comprehensive analysis is necessary to guide clinical decisions.

Our study was an up-to-date systematic review and meta-analysis comparing the outcomes of EVL and standard combination therapy in clinical trials. This review demonstrated that after successful EVL, no significant difference was observed in terms of initial hemostasis and 5-day rebleeding rates and mortality between the standard combination and EVL groups. However, sensitivity analysis of 5-day rebleeding suggested the presence of clinical heterogeneity. Specifically, after the study by Kumar et al. was excluded (14), the result favored standard combination therapy despite the findings of the study by Sung et al. (25), which was an obvious outlier among the studies. Hence, rebleeding outcomes must be interpreted cautiously.

Because all the included studies were randomized clinical trials that had a generally low risk of bias, other confounding factors should be considered. In this study, the most obvious characteristic causing heterogeneity is the long time frame because several modern treatment modalities such as multiband ligators, prophylactic antibiotics, and intravenous proton pump inhibitors were not widely available before the year 2000. Unlike the first two management methods that may directly help control varices and reduce portal hypertension, proton pump inhibitors may be useful for preventing post-ligation ulcer bleeding (33). In fact, in the trial by Lo et al. (12), a proton pump inhibitor was used in patients who did not receive vasoconstrictors. Because rebleeding after emergency EVL is frequently caused by ulcers (34), this factor should be considered during future trials.

In contrast to the rebleeding rate, our study showed similar 5-day and 6-week mortality rates and treatment failure rates between the standard combination and EVL groups. In prior systematic reviews, Banares et al. (17) did not report 6-week mortality, and Yan et al. only compared this outcome in patients who received a short course of treatment and those with standard use of vasoconstrictors. Although this analysis did not include the study by Sung et al. (25) because it only reported 30-day mortality, no significant difference ( $23 \%$ vs. $9 \%, p=0.09)$ was observed between the $\mathrm{EVL}$ and standard combination groups in the article. In the recent Baveno IV consensus (7), 6-week mortality was emphasized as the most crucial composite outcome. Hence, it is necessary for further studies incorporating this prognosis to evaluate the efficacy of vasoconstrictors in combination with EVL in detail.

The potential advantages of reducing the use of vasoconstrictors are fewer adverse events, lower cost, and shorter hospital stay. Although vasoconstrictor generally have a high safety profile and are welltolerated, the association with side effects, such as coronary ischemia and abdominal cramps, remains a 
concern. In this systematic review, only the study by Lo et al. (12) reported a significantly larger number of side effects in the standard group than in the EVL group without major morbidities. Thus, in patients with risk for ischemic heart disease or stroke, limiting vasoconstrictor use once hemostasis was achieved by EVL might be reasonable. Although the length of hospital stay was not significantly reduced in this study, reduced cost may result from lower use of vasoconstrictors without impairing the outcomes (15).

As previously mentioned, our study is the most comprehensive systematic review that compared the outcomes with and without vasoconstrictor use after EVL. Nevertheless, the study had limitations. First, the pooled estimates were undermined because of the small number of studies and high clinical heterogeneity. Despite our use of the random-effects model and sensitivity analysis, the result of 5-day rebleeding was equivocal. By contrast, the cumulative analysis suggested that if more recent studies were included, the pooled estimates moved toward the midline $(R R=1)$. Although the evidence is not sufficiently strong to prohibit the routine use of vasoconstrictors, use for up to 3 days with timely EVL and hemostasis is reasonable $(11,13,15)$. Second, different vasoconstrictors were used in each study, which may have confounded further analysis, although the effect might have been small (30). Third, most patients were classified as having Child-Pugh class B or C among the studies; furthermore, patients with hepatocellular carcinoma were excluded. However, a recent cohort study suggest endoscopic treatment alone may be feasible in patients with Child-Pugh class A with acute variceal bleeding (35). Additional large-scale, randomized trials are necessary for elucidating the aforementioned issues, and they may also verify the requirement for and optimal duration of vasoconstrictors in the future.

In conclusion, our study showed that in patients with acute esophageal variceal bleeding after EVL, 5-day and 6-week mortality rates were similar regardless of vasoconstrictor usage. However, given the controversial 5-day rebleeding rate, continuing vasoconstrictor use based on current evidence may be reasonable.

\section{Abbreviations}

EVL: Esophageal variceal ligation; EIS: endoscopic injection sclerosing therapy.

\section{Declarations}

Availability of data and materials: The datasets used and analyzed during the current study can be provided by the corresponding author on reasonable request.

Competing interests: The authors have no conflicts of interest to declare.

Funding. This study was supported by the EDAHP108008 project of E-Da Hospital granted to Dr. Jen-Hao Yeh. The funder had no role in designing the study, collecting and analyzing data, deciding to publish, or preparing the manuscript.

\section{Authors' contributions:}


Dr. Jen-Hao Yeh searched databases, reviewed articles, conducted statistical analysis, and wrote the manuscript. Dr. Gin-Ho Lo designed this study and was also responsible for database search, article review, and revision of the manuscript. Dr. Wen-Lun Wang reviewed the analyzed data and provided suggestions for manuscript writing. Dr. Ru-Yi Huang and Chih-Wen Lin provided suggestions and refined the statistical methodology. All authors have approved the final version of the article, including the authorship list.

Acknowledgement. We thank Dr. Po-Jen Hsiao for providing help with the discussion.

\section{References}

1. Garcia-Tsao G, Abraldes JG, Berzigotti A, Bosch J. Portal hypertensive bleeding in cirrhosis: Risk stratification, diagnosis, and management: 2016 practice guidance by the American Association for the study of liver diseases. Hepatology. 2017;65(1):310-35.

2. Chalasani N, Kahi C, Francois F, Pinto A, Marathe A, Bini EJ, et al. Improved patient survival after acute variceal bleeding: a multicenter, cohort study. American journal of gastroenterology. 2003;98(3):653-9.

3. Carbonell N, Pauwels A, Serfaty L, Fourdan O, Levy VG, Poupon R. Improved survival after variceal bleeding in patients with cirrhosis over the past two decades. Hepatology 2004;40(3):652-9.

4. Avgerinos A, Nevens F, Raptis S, Fevery J. Early administration of somatostatin and efficacy of sclerotherapy in acute oesophageal variceal bleeds: the European Acute Bleeding Oesophageal Variceal Episodes (ABOVE) randomised trial. Lancet 1997;350(9090):1495-9.

5. Zuberi BF, Baloch Q. Comparison of endoscopic variceal sclerotherapy alone and in combination with octreotide in controlling acute variceal hemorrhage and early rebleeding in patients with low-risk cirrhosis. American journal of gastroenterology. 2000;95(3):768-71.

6. Shah HA, Mumtaz K, Jafri W, Abid S, Hamid S, Ahmad A, et al. Sclerotherapy plus octreotide versus sclerotherapy alone in the management of gastro-oesophageal variceal hemorrhage. Journal of Ayub Medical College. 2005;17(1):10-4.

7. de Franchis R. Expanding consensus in portal hypertension: Report of the Baveno VI Consensus Workshop: Stratifying risk and individualizing care for portal hypertension. Journal of hepatology. 2015;63(3):743-52.

8. Lo GH, Lai KH, Cheng JS, Lin CK, Huang JS, Hsu PI, et al. Emergency banding ligation versus sclerotherapy for the control of active bleeding from esophageal varices. Hepatology 1997;25(5):1101-4.

9. Onofrio FQ, Pereira-Lima JC, Valenca FM, Azeredo-da-Silva ALF, Tetelbom Stein A. Efficacy of endoscopic treatments for acute esophageal variceal bleeding in cirrhotic patients: systematic review and meta-analysis. Endosc Int Open. 2019;7(11):E1503-e14.

10. Lo GH. Lack of difference among vasoconstrictors: Similar effectiveness or similar ineffectiveness? Hepatology 2015;62(2):653. 
11. Azam Z, Hamid S, Jafri W, Salih M, Abbas Z, Abid S, et al. Short course adjuvant terlipressin in acute variceal bleeding: A randomized double blind dummy controlled trial. Journal of hepatology. 2012;56(4):819-24.

12. Lo GH, Perng DS, Chang CY, Tai CM, Wang HM, Lin HC. Controlled trial of ligation plus vasoconstrictor versus proton pump inhibitor in the control of acute esophageal variceal bleeding. Journal of Gastroenterology and Hepatology 2013;28(4):684-9.

13. Chitapanarux T, Ritdamrongthum P, Leerapun A, Pisespongsa $P$, Thongsawat $S$. Three-day versus five-day somatostatin infusion combination with endoscopic variceal ligation in the prevention of early rebleeding following acute variceal hemorrhage: A randomized controlled trial. Hepatology Research. 2015;45(13):1276-82.

14. Kumar A, Jha SK, Mittal VV, Sharma P, Sharma BC, Sarin SK. Addition of Somatostatin After Successful Endoscopic Variceal Ligation Does not Prevent Early Rebleeding in Comparison to Placebo: A Double Blind Randomized Controlled Trial. Journal of Clinical and Experimental Hepatology. 2015;5(3):204-12.

15. Rengasamy S, Ali SM, Sistla SC, Lakshmi CP, Harichandra Kumar KT. Comparison of 2 days versus 5 days of octreotide infusion along with endoscopic therapy in preventing early rebleed from esophageal varices: a randomized clinical study. European journal of gastroenterology \& hepatology. 2015;27(4):386-92.

16. Salim A, Malik K, Haq IU, Butt AK, Alam A. Comparison of 12-Hour with 72-Hour Terlipressin Therapy for Bleeding Esophageal Varices. Journal of the College of Physicians and Surgeons-Pakistan 2017;27(6):334-7.

17. Banares R, Albillos A, Rincon D, Alonso S, Gonzalez M, Ruiz-del-Arbol L, et al. Endoscopic treatment versus endoscopic plus pharmacologic treatment for acute variceal bleeding: a meta-analysis. Hepatology. 2002;35(3):609-15.

18. Yan $\mathrm{P}, \mathrm{Tian} \mathrm{X}, \mathrm{Li} \mathrm{J}$. Is additional 5 -day vasoactive drug therapy necessary for acute variceal bleeding after successful endoscopic hemostasis? A systematic review and meta-analysis. Medicine. 2018;97(41).

19. Peng Y. Terlipressin in combination with endoscopic variceal ligation for prevention of acute esophageal variceal rebleeding. Chinese Journal of Gastroenterology. 2013;18(10):613-4+40.

20. Higgins JPT, Altman DG, Gøtzsche PC, Jüni P, Moher D, Oxman AD, et al. The Cochrane Collaboration's tool for assessing risk of bias in randomised trials. BMJ. 2011;343:d5928-d.

21. Efthimiou O. Practical guide to the meta-analysis of rare events. Evidence-based mental health. 2018;21(2):72-6.

22. Cornell JE, Mulrow CD, Localio R, Stack CB, Meibohm AR, Guallar E, et al. Random-effects metaanalysis of inconsistent effects: a time for change. Annals of internal medicine. 2014;160(4):267-70.

23. Egger M, Davey Smith G, Schneider M, Minder C. Bias in meta-analysis detected by a simple, graphical test. BMJ. 1997;315(7109):629-34. 
24. Higgins JPT. Commentary: Heterogeneity in meta-analysis should be expected and appropriately quantified. International Journal of Epidemiology. 2008;37(5):1158-60.

25. Sung JJ, Chung SC, Yung MY, Lai CW, Lau JY, Lee YT, et al. Prospective randomised study of effect of octreotide on rebleeding from oesophageal varices after endoscopic ligation. Lancet 1995;346(8991-8992):1666-9.

26. Lee GH, Cho SW, Kim HJ, Ko KH, Ko JH, Ko YY. Endoscopic Variceal Ligation plus Octreotide versus Variceal Ligation Alone for the Prevention of Early Rebleeding from Esophageal Varices. The Korean journal of hepatology. 1999;5(4):299-305.

27. Liberati A, Altman DG, Tetzlaff J, Mulrow C, Gotzsche PC, loannidis JP, et al. The PRISMA statement for reporting systematic reviews and meta-analyses of studies that evaluate health care interventions: explanation and elaboration. PLoS medicine. 2009;6(7):e1000100.

28. de Franchis R, Primignani M. Why do varices bleed? Gastroenterol Clin North Am. 1992;21(1):85-101.

29. D'Amico G, Pagliaro L, Pietrosi G, Tarantino I. Emergency sclerotherapy versus vasoactive drugs for bleeding oesophageal varices in cirrhotic patients. The Cochrane database of systematic reviews. 2010(3):1.

30. Seo YS, Park SY, Kim MY, Kim JH, Park JY, Yim HJ, et al. Lack of difference among terlipressin, somatostatin, and octreotide in the control of acute gastroesophageal variceal hemorrhage. Hepatology. 2014;60(3):954-63.

31. Avgerinos A, Armonis A, Stefanidis G, Mathou N, Vlachogiannakos J, Kougioumtzian A, et al. Sustained rise of portal pressure after sclerotherapy, but not band ligation, in acute variceal bleeding in cirrhosis. Hepatology. 2004;39(6):1623-30.

32. Laine L, Cook D. Endoscopic ligation compared with sclerotherapy for treatment of esophageal variceal bleeding. A meta-analysis. Ann Intern Med. 1995;123(4):280-7.

33. Kang SH, Yim HJ, Kim SY, Suh SJ, Hyun JJ, Jung SW, et al. Proton Pump Inhibitor Therapy Is Associated With Reduction of Early Bleeding Risk After Prophylactic Endoscopic Variceal Band Ligation: A Retrospective Cohort Study. Medicine. 2016;95(8):e2903.

34. Sinclair M, Vaughan R, Angus PW, Gow PJ, Parker F, Hey P, et al. Risk factors for band-induced ulcer bleeding after prophylactic and therapeutic endoscopic variceal band ligation. European journal of gastroenterology \& hepatology. 2015;27(8):928-32.

35. Monreal-Robles R, Cortez-Hernandez CA, Gonzalez-Gonzalez JA, Abraldes JG, Bosques-Padilla FJ, Silva-Ramos HN, et al. Acute Variceal Bleeding: Does Octreotide Improve Outcomes in Patients with Different Functional Hepatic Reserve? Ann Hepatol. 2018;17(1):125-33.

\section{Tables}

\section{Table 1. Designs and characteristics of the included studies}




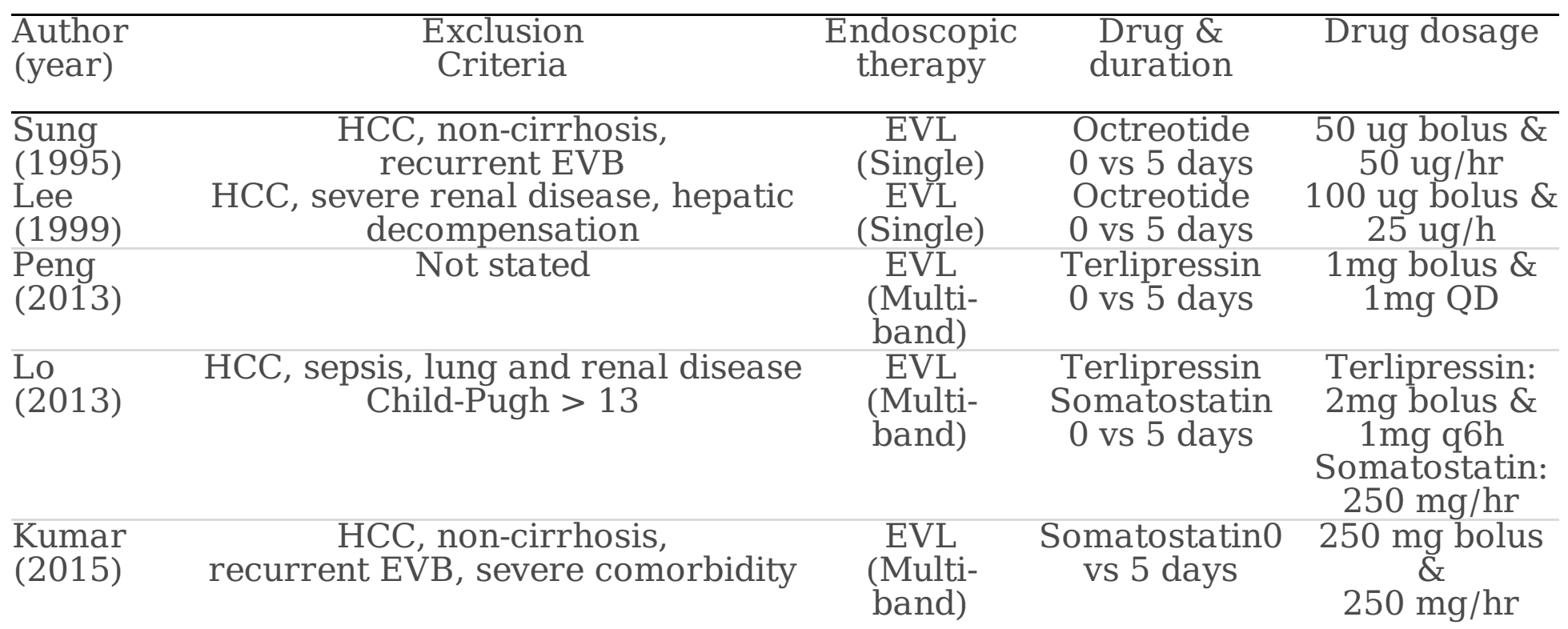

EVB: esophageal varices bleeding; HCC: hepatocellular carcinoma, EVL: endoscopic variceal ligation

Table 2. Intervention and number of patients with major outcomes in the included studies



Comb: combined endoscopic treatment and vaso-active agents; EVL: endoscopic variceal ligation only; N/A: not available

\section{Figures}




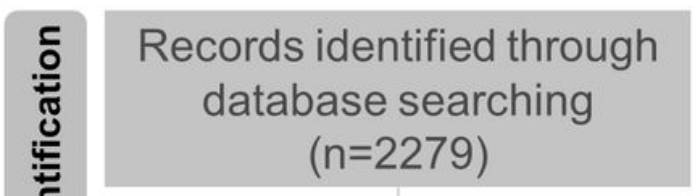

\section{Additional records identified through other sources} $(n=2279)$

$$
\text { Records identified }(n=2279)
$$$$
(n=0)
$$
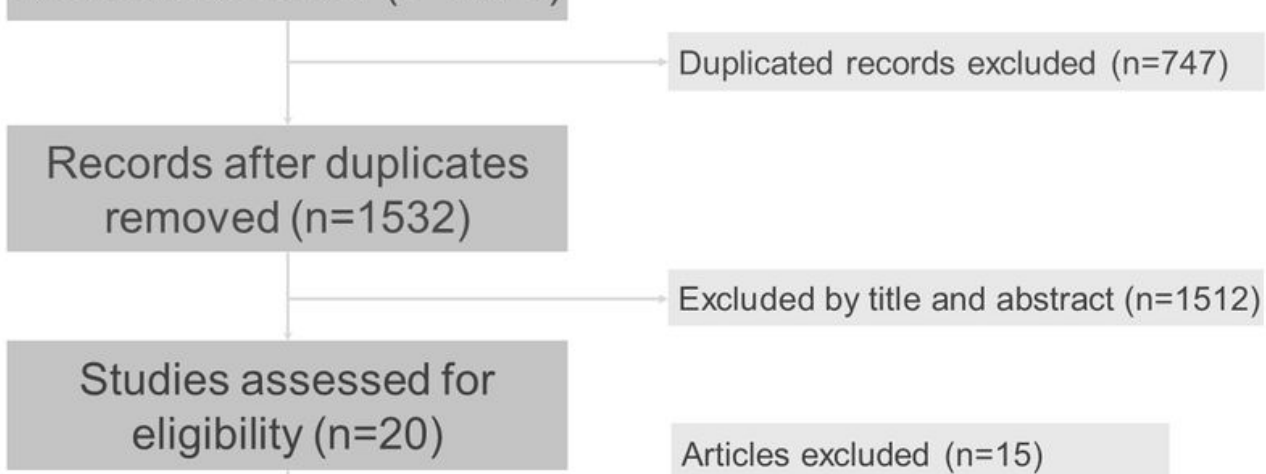

\section{Studies included in the review $(n=5)$}

Articles excluded $(n=15)$

4: vasoconstrictors in both arms

4: not full published paper

7: the same patient group as another eligible study

\section{Figure 1}

Preferred Reporting Items for Systematic Reviews and Meta-Analyses flowchart

\section{Figure 2a}

\begin{tabular}{lccc} 
Study name & & \multicolumn{3}{c}{ Statistics for each study } \\
\cline { 3 - 4 } & $\begin{array}{l}\text { Risk } \\
\text { ratio }\end{array}$ & $\begin{array}{c}\text { Lower } \\
\text { limit }\end{array}$ & $\begin{array}{c}\text { Upper } \\
\text { limit }\end{array}$ \\
Sung, 1995 & 0.978 & 0.888 & 1.076 \\
Lee, 1999 & 0.974 & 0.858 & 1.106 \\
Peng, 2013 & 1.000 & 0.961 & 1.041 \\
Lo, 2013 & 1.008 & 0.968 & 1.050 \\
Kumar, 2015 & 0.999 & 0.939 & 1.064 \\
& 1.001 & 0.976 & 1.025
\end{tabular}

Figure 2c

\begin{tabular}{llll} 
Study name & & \multicolumn{3}{c}{ Statistics for each study } \\
\cline { 3 - 5 } & $\begin{array}{c}\text { Risk } \\
\text { ratio }\end{array}$ & $\begin{array}{c}\text { Lower } \\
\text { limit }\end{array}$ & $\begin{array}{r}\text { Upper } \\
\text { limit }\end{array}$ \\
Lee, 1999 & 1.240 & 0.025 & 60.308 \\
Peng, 2013 & 1.000 & 0.020 & 49.396 \\
Lo, 2013 & 0.508 & 0.017 & 14.870 \\
& 0.814 & 0.096 & 6.875
\end{tabular}

Figure 2b

$\underline{\text { Risk ratio and } 95 \% \mathrm{Cl}}$

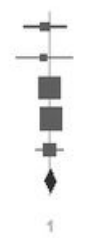

Favors EVL alone Favors combinatio
Study name

$\begin{aligned} \begin{array}{r}\text { Relative } \\ \text { weight }\end{array} & \\ 6.57 & \text { Sung, 1995 } \\ 3.76 & \text { Lee, 1999 } \\ 37.44 & \text { Peng, 2013 } \\ 36.86 & \text { Lo, 2013 } \\ 15.37 & \text { Kumar, 2015 }\end{aligned}$

Figure 2d

Risk ratio and $95 \% \mathrm{Cl}$

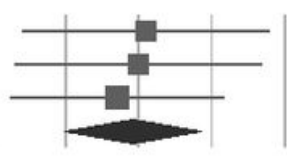

$\begin{array}{lllll}0.01 & 0.1 & 1 & 10 & 100\end{array}$

Favors EVL alone Favors combinatio

$\begin{aligned} \begin{aligned} \text { Relative } \\ \text { weight }\end{aligned} & \text { Study name } \\ 30.16 & \text { Lee, 1999 } \\ 29.92 & \text { Peng, 2013 } \\ 39.93 & \text { Lo, 2013 } \\ & \text { Kumar, 2015 }\end{aligned}$

\begin{tabular}{ccc}
\multicolumn{3}{c}{ Statistics for each study } \\
\cline { 2 - 3 } $\begin{array}{c}\text { Risk } \\
\text { ratio }\end{array}$ & $\begin{array}{c}\text { Lower } \\
\text { limit }\end{array}$ & $\begin{array}{c}\text { Upper } \\
\text { limit }\end{array}$ \\
3.200 & 0.382 & 26.781 \\
6.000 & 0.750 & 47.972 \\
0.517 & 0.048 & 5.551 \\
0.904 & 0.374 & 2.183 \\
1.436 & 0.549 & 3.758
\end{tabular}

Risk ratio and $95 \% \mathrm{Cl}$

$\begin{array}{ccc}\begin{array}{c}\text { Risk } \\ \text { ratio }\end{array} & \begin{array}{c}\text { Lower } \\ \text { limit }\end{array} & \begin{array}{c}\text { Upper } \\ \text { limit }\end{array} \\ 4.500 & 1.647 & 12.295 \\ 3.333 & 0.157 & 70.609 \\ 6.000 & 0.750 & 47.972 \\ 1.017 & 0.065 & 15.881 \\ 0.904 & 0.374 & 2.183 \\ 2.252 & 0.879 & 5.771\end{array}$
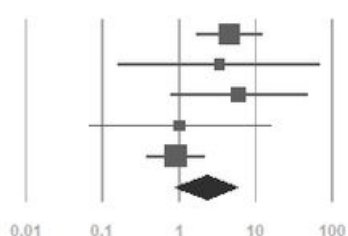

Favors EVL alone Favors combination

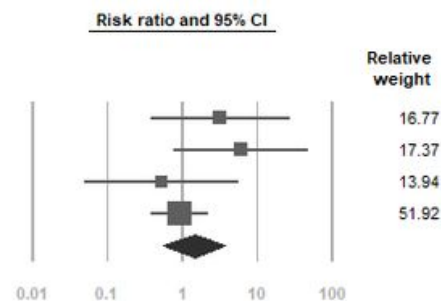

Relative weight 14.64 35.41 
Figure 2

a. Pooled risk ratio (RR) of initial hemostasis (Heterogeneity: $I 2=0 \%, \tau 2=0.0, p=0.970$ ); b. Pooled RR of rebleeding within 5 days. $(I 2=18.3 \%, \mathrm{\tau} 2=0.167, \mathrm{p}=0.290)$; $\mathrm{c}$. Pooled RR of mortality within 5 days $(\mathrm{I} 2=$ $0 \%, \tau 2=0, p=0.954)$; d. Pooled RR of treatment failure within 5 days $(12=0 \%, \tau 2=0, p=0.511)$. EVL: endoscopic variceal ligation.

Study name Statistics for each study

Risk ratio and $95 \% \mathrm{Cl}$

$\begin{array}{lcc}\text { Risk } & \text { Lower } & \text { Upper } \\ \text { ratio limit } & \text { limit }\end{array}$

Relative weight

$\begin{array}{lllr}\text { Lee, 1999 } & 1.667 & 0.058 & 47.648 \\ \text { Peng, 2013 } & 1.000 & 0.020 & 49.396 \\ \text { Lo, 2013 } & 0.776 & 0.181 & 3.317 \\ & 0.888 & 0.251 & 3.134\end{array}$
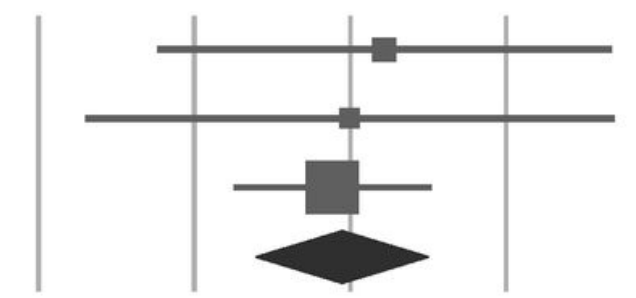

0.01
0.1

1

14.15 10.46 75.39

Favors EVL alone Favors combination

\section{Figure 3}

Pooled risk ratio of 6-week mortality (Heterogeneity: $I 2=0 \%, \tau 2=0, p=0.918$ ). EVL: endoscopic variceal ligation. 
Figure 4a

Study name

$\begin{array}{lccc} & \text { Point } & \begin{array}{c}\text { Lower } \\ \text { limit }\end{array} & \begin{array}{c}\text { Upper } \\ \text { limit }\end{array} \\ \text { Sung, 1995 } & 1.318 & 0.587 & 2.961 \\ \text { Lee, 1999 } & 2.205 & 0.746 & 6.516 \\ \text { Peng, 2013 } & 1.907 & 0.663 & 5.485 \\ \text { Lo, 2013 } & 2.520 & 0.849 & 7.485 \\ \text { Kumar, 2015 } & 4.026 & 1.760 & 9.209 \\ & 2.252 & 0.879 & 5.771\end{array}$

Statistics with study removed

5.771
Risk ratio $(95 \% \mathrm{Cl})$

with study removed



Favors EVL alone Favors combination

\section{Figure $4 b$}

Study name

Sung, 1995

Lee, 1999

Peng, 2013

Lo, 2013

Kumar, 2015
Cumulative statistics

$\begin{array}{ccc}\text { Lower } & \text { Upper } \\ \text { Point limit } & \text { limit }\end{array}$

$\begin{array}{llr}4.500 & 1.647 & 12.295 \\ 4.370 & 1.682 & 11.353 \\ 4.618 & 1.939 & 10.996 \\ 4.026 & 1.760 & 9.209 \\ 2.252 & 0.879 & 5.771 \\ 2.252 & 0.879 & 5.771\end{array}$

\section{Cumulative risk ratio $(95 \% \mathrm{Cl})$}

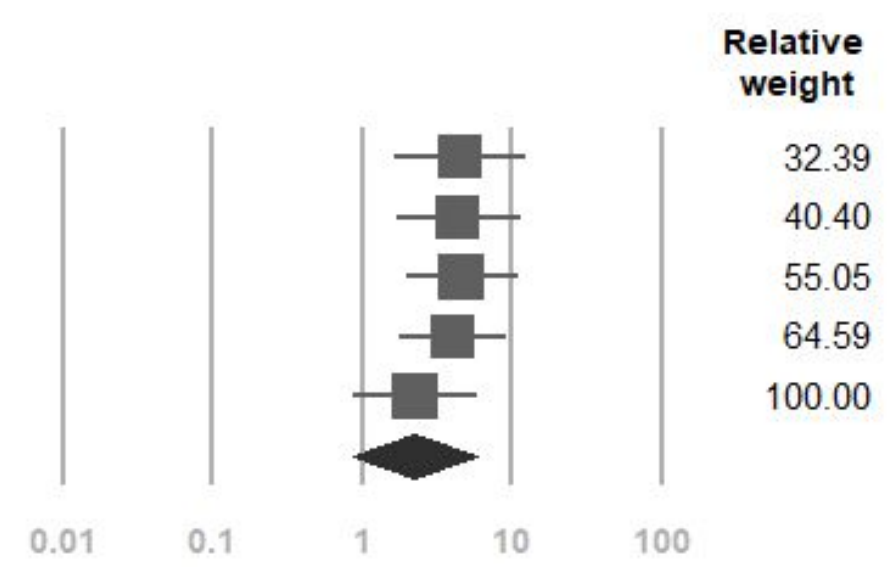

Favors EVL alone Favors combination

\section{Figure 4}

a. Sensitivity analysis for pooled risk ratio (RR) of 5-day rebleeding rate by excluding one study at a time;

b. Cumulative analysis for pooled RR of 5-day rebleeding rate. EVL: endoscopic variceal ligation.

\section{Supplementary Files}

This is a list of supplementary files associated with this preprint. Click to download.

- FigureS2.jpeg

- FigureS1.jpeg

- TableS2.docx 
- Tables1.docx

Page 16/16 